\title{
The Effect of Cerulenin on the Morphogenesis and Autolytic Activity of Bacillus subtilis
}

\author{
By H. J. ROGERS* AND P. F. THURMAN† \\ Biological Laboratory, The University of Kent at Canterbury, Kent CT2 7NJ, UK
}

(Received 25 June 1984; revised 26 October 1984)

\begin{abstract}
Partial inhibition of lipid synthesis in Bacillus subtilis by the inclusion of cerulenin in growth media led to the formation of chains of spheroidal cells both of wild-type strains and $l y t$ mutants. Washed cell suspensions prepared from wild-type cultures treated with cerulenin lysed only very slowly compared with those from control cultures although the activity of autolysins in $5 \mathrm{M}-\mathrm{LiCl}$ extracts made from such organisms was only about $30 \%$ less than those in extracts from controls. The behaviour of the cultures, such as the separation of cells and the reaction to $\beta$-lactams, was as if they were grossly deficient in autolytic activity. The concentration of cerulenin used $\left(7.5 \mu \mathrm{g} \mathrm{ml}^{-1}\right)$ reduced the growth rate two- to threefold but exponential growth at this slower rate continued for at least $18 \mathrm{~h}$. The steady state concentration of total protein and peptidoglycan per unit bacterial mass was the same as in control cultures but the phospholipid content was reduced by $50 \%$.
\end{abstract}

\section{INTRODUCTION}

Cerulenin interferes with fatty acid biosynthesis, and therefore with the formation of lipids, because it inhibits the condensing enzyme ( $\beta$-ketoacyl thioester synthetase) (Vance et al., 1972; Omura, 1976). It has also been shown, however, to inhibit the export of enzymes by a variety of Gram-positive bacterial species (Berkley et al., 1978; Caulfield et al., 1979; Fishman et al., 1980; Paton et al., 1980; Petit-Glatron \& Chambert, 1981; Leung et al., 1980; Jacques, 1983). Specific inhibition of incorporation of proteins into chromatophore membranes of Rhodopseudomonas spheroides has been reported (Broglie \& Niederman, 1979) as well as rather complex effects on lipid and protein biosynthesis in Streptococcus faecalis (Carson et al., 1981). Two examples of morphogenic effects by the antibiotic have also been noted, one in Mucor racemosus (Ito et al., 1982) and the other in Strep. faecalis (Higgins et al., 1980). These various phenomena have usually been ascribed to the primary inhibition of membrane lipid biosynthesis. However, some evidence has recently been produced (Petit-Glatron \& Chambert, 1981; Jacques, 1983) to suggest that the inhibition of the excretion of enzymes may not be related directly to fatty acid synthesis but rather to some other 'perturbation' of membrane structure caused by cerulenin (Jacques, 1983). Whatever its mechanism of action, cerulenin might be expected to have effects on wall synthesis by disturbing either the function or the distribution of the membrane-bound enzymes that synthesize wall polymers, as well as on the action of autolysins, since these must be exported through the cytoplasmic membrane to reach their substrates. The effects of cerulenin on wall and autolysin formation in Bacillus subtilis were examined, since extensive knowledge is available about the walls of this organism, and about both of the autolytic enzymes known to be present in strain 168, which have been isolated and characterized (Rogers et al., 1984).

\footnotetext{
† Present address: National Institute for Medical Research, Mill Hill, London NW7 1AA, UK.
} 


\section{METHODS}

Micro-organisms and growth media. The strains of Bacillus subtilis studied were 168 trpC, MB21 leu-8 metC 3 tall, FJ6 metC3 lyt2 (Fein \& Rogers, 1976) and W23. The growth media were as described by Rogers et al. (1983), together with beef-heart infusion medium (BHI; Difco) and an acid hydrolysed casein medium (CHSC; Janczura et al., 1961). When necessary, autotrophic requirements were met by the addition of sterile solutions of amino acids.

Culture conditions. Conical flasks, with attached side arms, containing one-fifth of their volume of medium, were incubated at $35^{\circ} \mathrm{C}$ and shaken to provide aeration. They were inoculated with exponentially growing cultures obtained as previously described (Rogers et al., 1983); with media allowing very fast growth this technique could not be used and either a fresh overnight culture or growth from an agar plate was used.

Lipids and lipid synthesis. Lipids were extracted and measured either after labelling with $\left[2-{ }^{3} \mathrm{H}\right]$ glycerol (Rogers et al., 1983), or by total phosphorus estimations. Protein and peptidoglycan synthesis were measured as before (Rogers et al., 1983).

Bacterial morphology. Bacterial dimensions were measured with a split-image eyepiece (Rogers \& Thurman, 1978), and the results were expressed either as length to width ratios, or directly as arbitrary 'eye-piece' units. Each value recorded represents the mean of measurements on 20 individual bacteria.

Bacterial autolysis. Samples of cultures $(5-10 \mathrm{ml})$ were filtered through $0.45 \mu \mathrm{m}$ Millipore filters and the bacteria were washed with an equal volume of the appropriate (see below) buffer. The washed bacteria were suspended in either $25 \mathrm{~mm}$-borate buffer $\mathrm{pH} 9.5$ to measure the autolytic amidase or $50 \mathrm{~mm}$-succinate/ $\mathrm{NaOH}$ buffer $\mathrm{pH} 5.5$ to measure the $\beta-N$-acetylglucosaminidase. The suspensions were warmed to $35^{\circ} \mathrm{C}$ and the $\mathrm{OD}_{675}$ values measured at frequent intervals using a Pye-Unicam 60 spectrophotometer. Autolytic activity was measured from the initial slopes of the curves plotted from the data and was expressed as percentage reduction in $\mathrm{OD}_{675} \min ^{-1}$. Within any given experiment the agreement between replicates was excellent, showing for six measurements a coefficient of variation of $6 \%$ (on a mean value of $2 \cdot 8$ ). Between experiments replication was less good, with a coefficient of variation of $28 \cdot 7 \%$ over 15 experiments with a mean value of $2 \cdot 1$.

Extraction and measurement of autolytic enzymes. Samples $(40-50 \mathrm{ml})$ of cultures were centrifuged at $5000 \mathrm{~g}$ for $10 \mathrm{~min}$ and the bacteria washed with an equal volume of cold $25 \mathrm{mM}-\mathrm{Tris} / \mathrm{HCl}$ buffer $\mathrm{pH} 7 \cdot 2$. The washed bacteria were then transferred to small microfuge (MSE) tubes and the volumes adjusted to $250 \mu \mathrm{l}$ with the same buffer. An equal volume of cold $10 \mathrm{M}-\mathrm{LiCl}$ was added, the contents of the tubes were thoroughly mixed and the $\mathrm{OD}_{675}$ of $1: 100$ dilutions measured. All the suspensions were adjusted by the addition of $5 \mathrm{M}$ - $\mathrm{LiCl}$ in $25 \mathrm{mM}$ - Tris/ $\mathrm{HCl}$ buffer $\mathrm{pH} 7 \cdot 2$ to the same value and they were stored at $0-4{ }^{\circ} \mathrm{C}$ for $1 \mathrm{~h}$. The suspensions were then centrifuged for $10 \mathrm{~min}$ at $11-12000 \mathrm{~g}$ and the supernatant solutions diluted $1: 5$ in buffer. In this state the samples could be stored for several days at $0-4{ }^{\circ} \mathrm{C}$ without loss of enzyme activity. The activities of the extracts were measured by adding $100 \mu \mathrm{l}$ to one of the following solutions warmed to $35^{\circ} \mathrm{C}$ : (a) $500 \mu \mathrm{l} 50 \mathrm{mM}$-borate buffer pH 9.5, $20 \mu 11 \mathrm{M}-\mathrm{MgCl}_{2}$, $330 \mu \mathrm{l} 25 \mathrm{mM}$-Tris/HCl buffer $\mathrm{pH} 7.2$ and $50 \mu \mathrm{l}\left[{ }^{1+} \mathrm{C}\right.$ ]SDS-walls from B. subtilis 168 (Rogers et al., 1984); (b) $375 \mu \mathrm{l}$ $50 \mathrm{~mm}$-succinate/ $\mathrm{NaOH}$ buffer pH 5.5 and $25 \mu \mathrm{l}\left[{ }^{1+} \mathrm{C}\right] \mathrm{SDS}$-walls from Micrococcus luteus (Rogers et al., 1984). At intervals, $100 \mu \mathrm{l}$ samples were taken, centrifuged for $10 \mathrm{~min}$ at $11-12000 \mathrm{~g}$ and $50 \mu \mathrm{l}$ samples of the supernatant fluids estimated for radioactivity. The results were expressed as the percentage of the radioactive wall appearing in the supernatant fluid $\min ^{-1} \times 1000$ divided by the $O_{675}$ value of the original suspension that had been extracted with $\mathrm{LiCl}$. The coefficient of variation for the activities of extracts from culture to culture of the same strain, 168 , growing in the same medium (CHSC) measured in 11 cultures over a period of one year was $28 \%$. Within any one experiment the variation was less than $10 \%$.

Preparation and analysis of SDS-walls. Bacterial cell walls were prepared, treated with SDS, hydrolysed with $\mathrm{HCl}$ and analysed as previously described (Fein \& Rogers, 1976; Rogers \& Taylor, 1978).

Radioactive measurements. Radioactivity in solutions was measured as previously described (Rogers et al., 1983).

Chemicals. Cerulenin was obtained from Sigma and stock solutions of $1 \mathrm{mg} \mathrm{ml}^{-1}$ in absolute ethanol were stored at $-20^{\circ} \mathrm{C}$ for no more than one week. $\mathrm{N}$-Acetylmuramyl-L-alanine amidase (amidase) was made as previously described (Rogers et al., 1984).

\section{RESULTS \\ Effects of cerulenin on morphology}

In the presence of $7.5 \mu \mathrm{g}$ cerulenin $\mathrm{ml}^{-1}$, cultures of strains $168, \mathrm{MB} 21$ and the autolysin deficient strain FJ6 in minimal MSM or in CHSC media, continued to grow exponentially but at about a half to one-third of the rate in the control cultures. The doubling time of strain FJ6 growing in minimal (MSM) medium was increased threefold (SD 0.49) and that of strain MB21 2.3-fold (SD 0.48). The results are for 15 experiments on each strain. After about two generations the normally rod-shaped organisms started to become round. After $18 \mathrm{~h}$ incubation, all the 

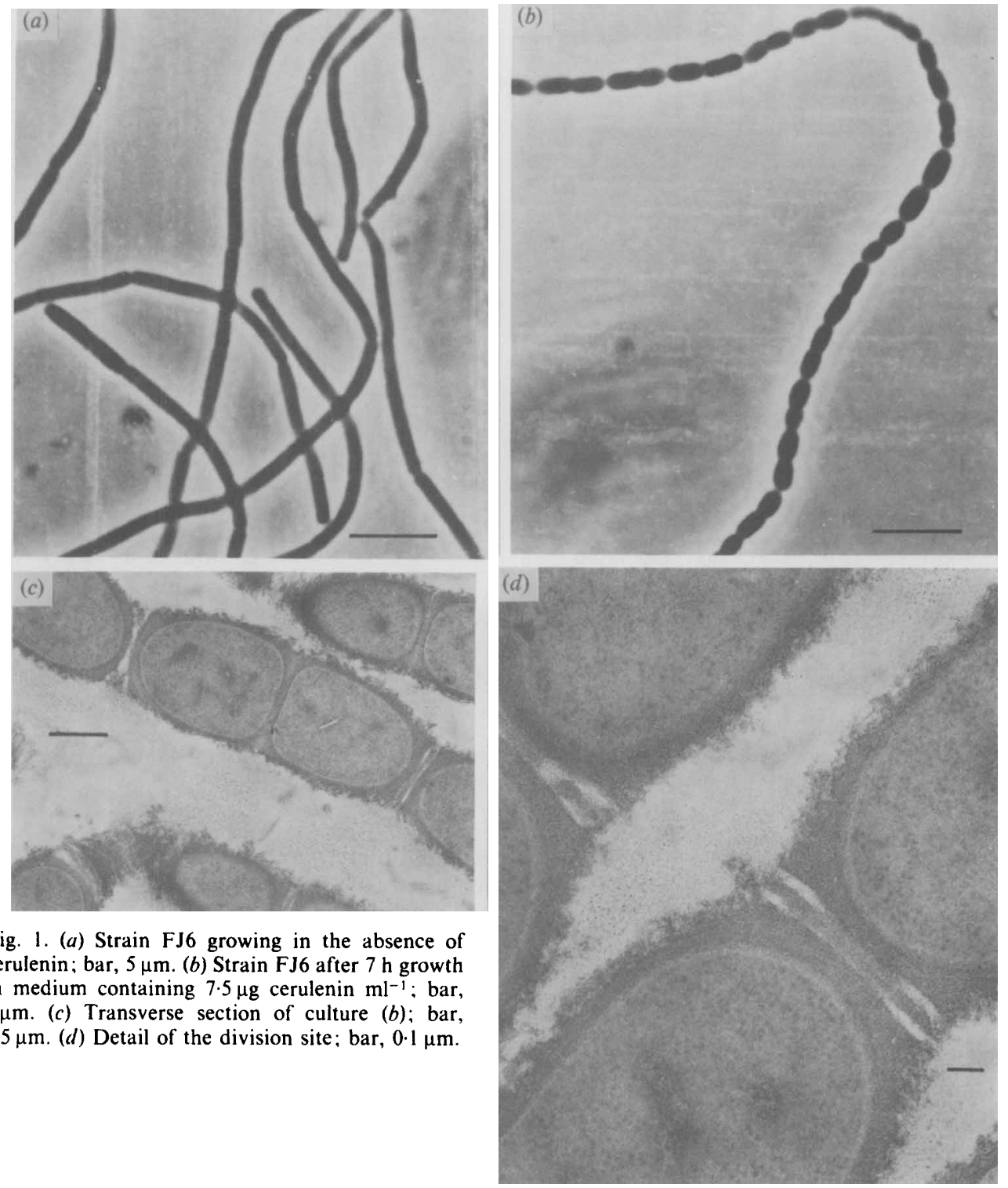

Fig. 1. (a) Strain FJ6 growing in the absence of cerulenin; bar, $5 \mu \mathrm{m}$. (b) Strain FJ6 after 7 h growth in medium containing $7.5 \mu \mathrm{g}$ cerulenin $\mathrm{ml}^{-1}$; bar, $5 \mu \mathrm{m}$. (c) Transverse section of culture $(b)$; bar, $0.5 \mu \mathrm{m}$. (d) Detail of the division site; bar, $0.1 \mu \mathrm{m}$.

bacteria still appeared as cocci when examined by phase-contrast microscopy (Fig. $1 b$ ). Longitudinal sections under the electron microscope showed mostly ovoid cells with a few truly spherical forms (Fig. 1c). The septa, usually sharply perpendicular to the side walls in strain FJ6 (Rogers et al., 1983), had become curved and deep clefts marked the division sites along the chain of cells with what appeared to be discs of material separating the older cell poles (Fig. $1 d$ ). The individual cells of strain 168 (the wild-type) grown with cerulenin were similar to those of strain FJ6. These were also arranged as chains of 12-15 unseparated individuals. In the absence of cerulenin, strain 168 grew as rods either singly or in pairs. Measurement of the cell dimensions of the wild-type strain 168 growing in MSM medium containing $7.5 \mu \mathrm{g}$ cerulenin $\mathrm{ml}^{-1}$ showed a steady decline in axial ratios (Fig. 2). The reduction of the ratios was almost entirely due to a decrease in cell length rather than an increase in diameter (Fig. 3). This effect was reversible, and when the coccal-shaped cells were filtered on to Millipore filters and resuspended in the 


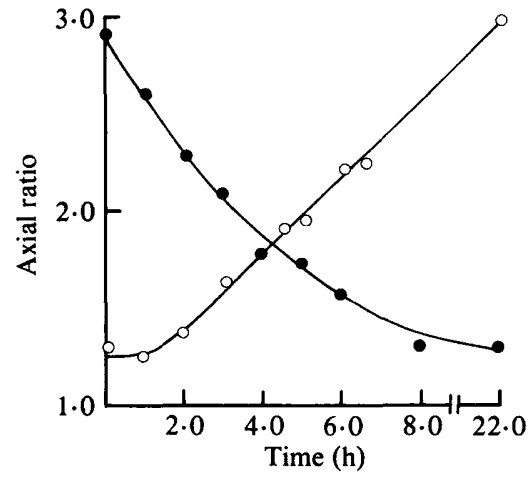

Fig. 2

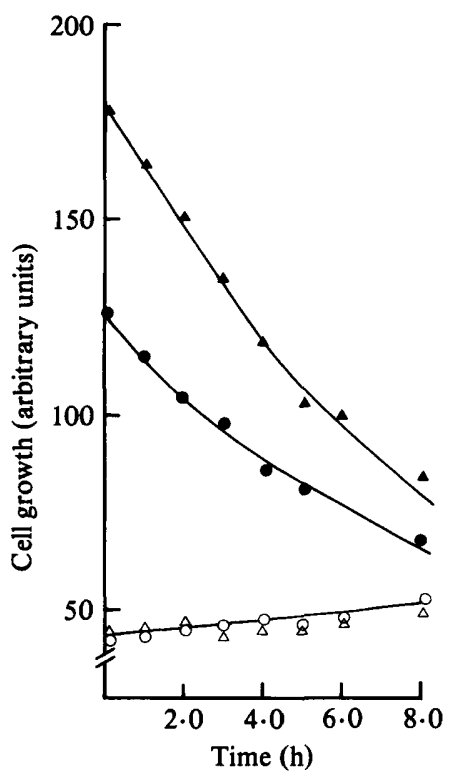

Fig. 3

Fig. 2. Effect of $7 \cdot 5 \mu \mathrm{g}$ cerulenin $\mathrm{ml}^{-1}$ on the axial ratios of strain 168 growing in minimal MSM medium (O) and recovery after removal of the antibiotic $(O)$. Each point represents the mean value for the measurement of 20 individuals.

Fig. 3. Changes in length $(O, \Delta)$ and width $(O, \triangle)$ of cells of strain 168 growing in MSM $(O, O)$ or CHSC $(\triangle, \Delta)$ medium containing $7 \cdot 5 \mu \mathrm{g}$ cerulenin $\mathrm{ml}^{-1}$.

same medium not containing cerulenin, the lengths and therefore the axial ratios of the cells again increased (Fig. 2). The growth rate recovered more slowly than the morphology. Similar results were obtained in CHSC medium but were less marked in BHI medium. The rounding-up of the cells that occurred during growth with cerulenin was not simply due to the slower growth rate. When the exponential growth rates of strains FJ6 or 168 growing in MSM medium were reduced two- to threefold by adding either chloramphenicol $\left(1 \mu \mathrm{g} \mathrm{ml}^{-1}\right)$ phenylethyl alcohol $\left(1.8 \mathrm{mg} \mathrm{ml}^{-1}\right)$ or cephalothin $\left(0.02-0.03 \mu \mathrm{g} \mathrm{ml}^{-1}\right)$ or the growth temperature was lowered from 35 to $25^{\circ} \mathrm{C}$ no rounding of the cells could be seen under the phase-contrast light microscope. Attempts to reproduce the morphological effect of cerulenin using strain W23 were almost entirely negative. Growing in MSM medium, strain W23 was much more sensitive than any of the other strains, and $7.5 \mu \mathrm{g}$ cerulenin $\mathrm{ml}^{-1}$ completely stopped growth whilst at lower concentrations, such as 2.5 or $5 \mu \mathrm{g} \mathrm{ml}^{-1}$, although the growth rate was reduced to about $50 \%$ of that of the control culture, no morphological effect was demonstrated. A small change of axial ratios was found with $7.5 \mu \mathrm{g}$ cerulenin $\mathrm{ml}^{-1}$, from 3.55 to 2.28 after $8 \mathrm{~h}$ incubation, although growth had stopped about $2 \mathrm{~h}$ after addition of the antibiotic.

The effects of $7.5 \mu \mathrm{g}$ cerulenin $\mathrm{ml}^{-1}$ on the shape of strains 168 or FJ6 could be reversed by the simultaneous addition of either Tween 20 at $0.5-2.5 \%(\mathrm{v} / \mathrm{v})$ or Tween 80 at $5 \%(\mathrm{v} / \mathrm{v})$. The inhibition of growth rate was partially prevented by these polyoxyethylene esters. Neutral detergents such as Nonidet, Brij 35, Brij 58 or Triton X-100 inhibited growth and induced lysis. The effect of fatty acids themselves, such as dodecanoic acid, have not been examined in detail since they too caused lysis of the cultures.

\section{Inhibition of autolysin}

The rates of autolysis at $\mathrm{pH} 9.5$ of washed suspensions of bacteria decreased rapidly after $7 \cdot 5 \mu \mathrm{g}$ cerulenin $\mathrm{ml}^{-1}$ had been added to exponentially growing cultures of strain 168 in CHSC or BHI media (Table 1). Addition of this concentration of cerulenin to the suspensions themselves 
Table 1. Inhibition of autolysis at pH 9.5 of washed suspensions by growth with cerulenin

Cerulenin $\left(7.5 \mu \mathrm{g} \mathrm{m}^{-1}\right)$ was added to exponential cultures of $B$. subtilis strain 168 growing in either CHSC or BHI media. Each medium was tested in duplicate. The results are given as mean values; ND, not done.

\begin{tabular}{|c|c|c|c|c|c|}
\hline \multirow{2}{*}{$\begin{array}{l}\text { Time } \\
(\min )\end{array}$} & \multirow[b]{2}{*}{ Medium } & \multicolumn{2}{|c|}{ Units of activity } & \multicolumn{2}{|c|}{ Activity remaining $(\%)$} \\
\hline & & CHSC & BHI & CHSC & BHI \\
\hline 0 & & $3 \cdot 5$ & 1.66 & & \\
\hline 20 & & 1.5 & 1.02 & 43 & 61 \\
\hline 40 & & 1.0 & 0.5 & 29 & 30 \\
\hline 60 & & $0 \cdot 6$ & $0 \cdot 1$ & 17 & 6 \\
\hline 100 & & $0 \cdot 2$ & ND & 6 & ND \\
\hline
\end{tabular}

had no effect on the rates of autolysis. Addition of alcohol to the growth medium at the same concentration as that introduced to the culture with the cerulenin also had no effect. The doubling time of strain 168 in CHSC medium is 35 min so that in the presence of cerulenin about half the autolytic activity is lost in half a generation time, since the antibiotic decreases the growth rate about $2 \cdot 5$-fold.

When suitable concentrations of $\beta$-lactams are added to cultures of strains FJ6 or MB21, particularly when grown in BHI medium, the optical density continues to increase for about $40 \mathrm{~min}$ until it has about doubled and then it decreases (Rogers et al., 1983). When cerulenin $\left(7.5 \mu \mathrm{g} \mathrm{ml}^{-1}\right)$ was present as well as $\beta$-lactam $\left(0.2 \mu \mathrm{g} \mathrm{ml}^{-1}\right.$; cephalothin), the optical density increased three- or fourfold and there was no subsequent reduction for several hours. This was still so even at very high concentrations of $\beta$-lactam. When the bacteria were filtered $40 \mathrm{~min}$ after adding the antibiotics, washed and resuspended in alkaline buffer those cultures containing only $\beta$-lactam lysed more rapidly than the suspensions from control cultures due to the action of the amidase, whereas when cerulenin had been present during growth they lysed much more slowly (Fig. 4). $\beta$ - $N$-Acetylglucosaminidase is a very much less active component of the autolytic system, which made measurements difficult, but the results for the lysis of the cells suspended in acid buffers were qualitatively similar.

It proved impossible to do these sorts of experiments with strain 168 because when cephalothin alone was present in the cultures, lysis was too rapid to make the preparation of suspensions feasible. The compromise of using less lytic strains such as FJ6 and MB21 but rich media such as BHI gave measurable autolytic rates without making the preparation of suspensions difficult. It had disadvantages, however, two of which were the occasionally decreased effect of cerulenin found in rich media and the non-linearity of the curves for autolysis of suspensions even during short periods when cerulenin had been present in the growth medium (Fig. 4).

Changes in the rates of autolysis of cell suspensions could be due either to the presence of a bacterial wall that is more or less susceptible to the same amount of lytic enzymes or to the formation or export through the cytoplasmic membrane of different amounts of active autolysins. To distinguish between these possibilities, bacteria from cultures containing cerulenin, with or without cephalothin, together with the appropriate controls were separated by filtration $40 \mathrm{~min}$ after adding the antibiotics, washed, and the autolytic enzymes extracted with $5 \mathrm{M}-\mathrm{LiCl}$ and their activities estimated. There was less amidase in the cultures that had contained cerulenin than in those that had not (Table 2). Comparison of the results in Tables 1 and 2 shows however that cerulenin had much more effect on the rate of autolysis of cell suspensions of strain 168 prepared $40 \mathrm{~min}$ after addition of the antibiotic than it had on the activity of the amidase extracted by $\mathrm{LiCl}$. This difference also appeared to be true for strain MB21 where inhibition of cell autolysis after 40 min exposure was $70 \%$ compared with $23 \%$ for the extracts. A difference was not observed with strain FJ6; further work with autolysin deficient mutants would be required before the significance of this finding could be commented upon. Comparison of $\mathrm{LiCl}$ extracts prepared from cultures of strain MB21 treated with cephalothin alone with those from controls gave exceedingly variable results. In 15 such 


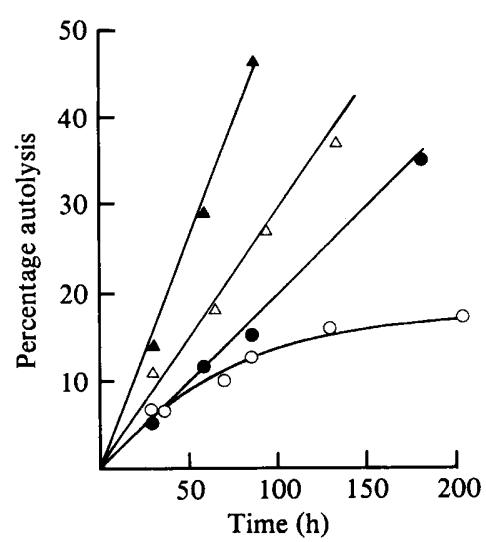

Fig. 4

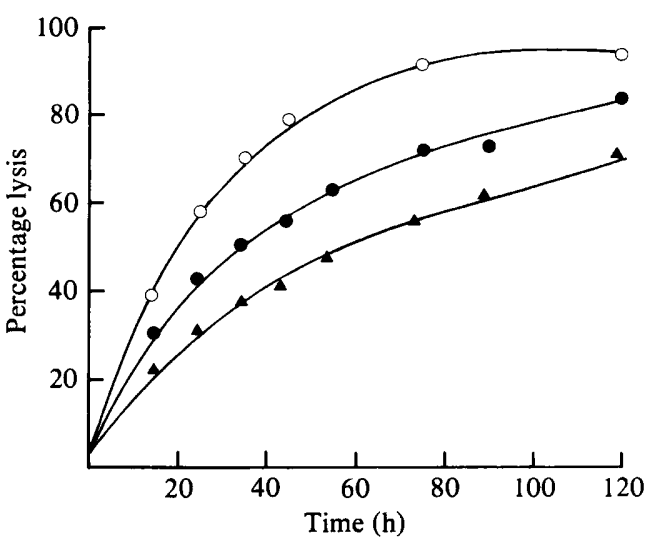

Fig. 5

Fig. 4. Effect of $7.5 \mu \mathrm{g}$ cerulenin $\mathrm{ml}^{-1}$ in BHI medium upon autolysis of a cell suspension of strain MB21 at $\mathrm{pH} 9.5$ in the absence $(O)$ and presence $(\triangle)$ of $0.2 \mu \mathrm{g}$ cephalothin $\mathrm{ml}^{-1}$ and comparison with autolysis of suspensions of bacteria grown with neither antibiotic $(O)$ or with $0.2 \mu \mathrm{g}$ cephalothin $\mathrm{ml}^{-1}$ alone $(\Delta)$. The bacteria were collected by filtration $40 \mathrm{~min}$ after the addition of the antibiotic.

Fig. 5. Lysis of SDS-walls from $B$. subtilis 168 incubated for $40 \mathrm{~min}$ after the addition of $10 \mu \mathrm{g}$ cerulenin $\mathrm{ml}^{-1}(\Delta)$ or $0.2 \mu \mathrm{g}$ cephalothin $\mathrm{ml}^{-1}(\mathrm{O})$ compared with the lysis of those prepared from exponentially growing control cells $(O)$ by purified amidase $\left(2\right.$ units $\left.\mathrm{ml}^{-1}\right)$ from the same organisms acting at $\mathrm{pH} 9 \cdot 5$ in the presence of $10 \mathrm{mM}-\mathrm{MgCl}_{2}$.

Table 2. Effect of cerulenin on the activity of amidase in LiCl extracts of B. subtilis strains

Cerulenin $\left(7.5 \mu \mathrm{g} \mathrm{ml}^{-1}\right)$ was added to exponentially growing cultures. The bacteria were removed by centrifuging $40 \mathrm{~min}$ later and extracted at $0-4{ }^{\circ} \mathrm{C}$ with $5 \mathrm{M}-\mathrm{LiCl}$. Control and cerulenin treated cultures were always tested in the same experiment. The number of experiments is given in parentheses.

\begin{tabular}{|c|c|c|c|c|}
\hline \multirow[b]{2}{*}{ Strain } & \multirow[b]{2}{*}{ Medium } & \multicolumn{2}{|c|}{ Units of amidase activity } & \multirow{2}{*}{$\begin{array}{c}\text { Percentage } \\
\text { activity in } \\
\text { cerulenin cultures }\end{array}$} \\
\hline & & Control & + Cerulenin & \\
\hline 168 & CHSC & $9 \cdot 0$ & $6 \cdot 1$ & $68(2)$ \\
\hline & BHI & 5.4 & 3.7 & $66(3)$ \\
\hline MB21 & BHI & $1 \cdot 3$ & 1.0 & $67(3)$ \\
\hline FJ6 & BHI & 0.8 & $0 \cdot 25$ & $31(1)$ \\
\hline
\end{tabular}

comparisons the average amidase activity was $28 \%$ greater in the extracts from the penicillin treated bacteria but the variation was from zero to $50 \%$. It is supposed that such bacteria are unstable, due to the treatment with $\beta$-lactam, and are damaged by preparing the cells for $\mathrm{LiCl}$ extraction.

From another set of similar cultures, bacteria were again harvested $40 \mathrm{~min}$ after adding the antibiotics and SDS-walls were prepared from them. The rate of lysis of these preparations by a sample of purified amidase was measured. The walls from the organisms incubated with cephalothin $\left(0.2 \mu \mathrm{g} \mathrm{ml}^{-1}\right)$ were more susceptible than those from the control cells. The initial rate of hydrolysis of these walls was $25 \%$ faster than those from control cells, whilst those from cultures incubated with cerulenin were somewhat less sensitive, the initial rates of hydrolysis being $71-73 \%$. When both cerulenin and cephalothin had been present, the walls were equally susceptible as those from the control bacteria (Fig. 5). Chemical analysis of the walls from cerulenin treated bacteria showed no differences from the controls in any of the peptidoglycan or teichoic acid constituents.

The addition of Tween 20 to cultures containing cerulenin partially reversed the effect of the inhibitor on cell autolysis. In these experiments, the cultures were first incubated in the presence of cerulenin for $40 \mathrm{~min}$, the Tween 20 solution was added and incubation then continued. Samples were taken at intervals and the rates of cell autolysis measured as before. 
Effect of cerulenin on lipid synthesis

The amount of extractable lipid per $\mathrm{OD}_{675}$ unit in the cultures treated with cerulenin $\left(7.5 \mu \mathrm{g} \mathrm{ml}^{-1}\right)$ reached a steady value which was about $50 \%$ of that in the control cells, whether measured by radioactivity incorporated from $\left[2-{ }^{3} \mathrm{H}\right]$ glycerol or by total phosphorus. The mean results for the two methods of lipid measurement were $52.6 \%$ and $53.0 \%$ respectively.

\section{Effect of cerulenin on protein and peptidoglycan synthesis}

When protein synthesis was measured by the incorporation of $\mathrm{L}-\left[4,5-{ }^{3} \mathrm{H}\right]$ leucine during three generations of growth, cerulenin $\left(7.5 \mu \mathrm{g} \mathrm{ml}^{-1}\right)$ had no effect upon the amount of radioactivity incorporated per $\mathrm{OD}_{675}$ unit of the cultures. The ratios of the values of d.p.m. incorporated/ $\mathrm{OD}_{675}$ for the control and cerulenin cultures had a mean of 1.04 (SD \pm 0.094 ). Peptidoglycan synthesis was measured by the incorporation of $N$-acetyl- $\left[1-{ }^{14} \mathrm{C}\right]$ glucosamine into peptidoglycan isolated from the bacteria. The effect of cerulenin was assessed by the same criterion as that used for protein biosynthesis; the average ratio between control and cerulenin containing cultures was $1.08( \pm 0.22)$. There was more scatter of these results than of those for protein biosynthesis but again there was no evidence for a specific effect on peptidoglycan synthesis.

\section{DISCUSSION}

The concentration of cerulenin used in this work reduced the growth rate of cultures but growth continued exponentially for at least $18 \mathrm{~h}$. Thus in the antibiotic treated cultures new steady states were established. This is a different approach from other work using either cell suspensions (Paton et al., 1980) or a sufficiently high concentration of cerulenin to stop growth within less than a generation (Caulfield et al., 1979; Carson et al., 1981). The new steady state established was such that the proportions of total protein and peptidoglycan were the same as those in the control cultures but the content of phospholipid was reduced by about $50 \%$. Since a very high proportion, if not all, of the phospholipid in most Gram-positive bacteria arises from the cytoplasmic membrane it would seem likely that the phospholipid to protein ratio of this membrane has been decreased. Paton et al. (1980) found a decrease from a ratio of 1.03 to 0.70 in the cytoplasmic membrane during $3 \mathrm{~h}$ treatment of Bacillus amyloliquefaciens with cerulenin, with no decrease in the synthesis of membrane proteins. In this new steady state in the presence of cerulenin the bacteria showed three characteristics for wild-type and parental strains (168 and MB21) as well as for an autolysin deficient mutant. The cells appeared as spheroids not rods, the rate of autolysis of cell suspensions was very greatly reduced, and there was a small reduction in the activity of lytic enzymes extracted from the cells by strong $\mathrm{LiCl}$ solutions. The shape changes and the loss of autolytic ability caused by cerulenin were reversed by Tween 20 or Tween 80 , as were the morphological effects and the suppression of ornithine decarboxylase in Mucor racemosus (Ito et al., 1982). It is presumed that the Tweens supply an assimilable form of fatty acids, thus overcoming the inhibition of their synthesis by cerulenin. It is tempting to suppose that the export of proteins, the morphological effect and the inhibition of autolysis are all related rather directly to the reduced lipid synthesis. It is encouraging that the rod to spheroid change in $\operatorname{rod} B$ conditional mutants is also accompanied by rather large changes in the rate of phospholipid synthesis, the steady state membrane lipid/protein ratio and lipid turnover (Rogers, 1985). The smallness of the loss of extractable activity of autolysins in cerulenin grown cells compared with that extracted from the controls might be more problematic if more was known about the location of the proteins extracted. At least 12 proteins are present in the extracts from $B$. subtilis (H. J. Rogers \& C. Taylor, unpublished work) and it is probable that some of these arise from sites other than the walls of the organisms. The inhibition by cerulenin of exported enzymes already referred to in the Introduction is probably concerned with some step involved in the export process itself rather than in synthesis. Other aspects of protein formation such as enzyme induction (Caulfield et al., 1979) or membrane protein synthesis (Paton et al., 1980) are not affected, although a rapid decrease of RNA synthesis has been claimed by Willie et al. (1975) in B. subtilis as either a direct or an indirect effect of treatment with cerulenin. The half-life of mRNA on the other hand is not affected (Petit-Glatron \& 
Chambert, 1981). If the effect of cerulenin is on export of the autolysins rather than on their formation then $\mathrm{LiCl}$ solutions may be extracting active non-exported enzyme from the cells which cannot reach the walls, thus accounting for the relatively active extracts despite the very slow autolysis of suspensions.

Cerulenin not only interferes with the biosynthesis of common phospholipid but also with that of lipoteichoic acid in Strep. faecalis (Carson et al., 1981). If lipoteichoic acid regulates the action of some autolysins by inhibiting them then an activation of autolysins might have been expected as a result of treating cells with cerulenin; this did not occur in Strep. faecalis or in B. subtilis where lipoteichoic acid inhibits the endo- $\beta$ - $N$-acetylglucosaminidase but not the amidase (Rogers et al., 1984). The expression of both enzymes in washed suspensions of $B$. subtilis grown with cerulenin is inhibited.

Washed cell suspensions are nevertheless artificial situations to test for autolysins and do not necessarily reflect the action of the enzymes in growing cells. However, the two roles in growing cultures that were tested here, namely in the separation of cells during division and in the lysing of bacteria treated with antibiotics that inhibit cell wall formation, accurately reflected the inhibition of cell suspension autolysis caused by growth with cerulenin. Separation of wild-type cells was inhibited and relatively high concentrations of antibiotics caused no lysis of autolysin deficient mutants. That cerulenin can inhibit antibiotic induced lysis of Escherichia coli has already been reported by Leduc et al. (1982).

Our thanks are due to Dr I. D. J. Burdett, National Institute for Medical Research, London NW7 1AA, UK, for the pictures in Figs $1(c)$ and $(d)$.

\section{REFERENCES}

Berkeley, R. C. W., Pepper, E. A., Caulfield, M. P. \& Melling, J. (1978). Inhibition of enterotoxin A production by cerulenin and quinacrine. Presumptive evidence for a lipid intermediate protease release mechanism. FEMS Letters 4, 103 107.

Broglie, R. M. \& Niederman, R. A. (1979). Membranes of Rhodopseudomonas spheroides: effect of cerulenin on assembly of chromatophore membrane. Journal of Bacteriology 138, 788-798.

(arson, D. D., Pieringer. R. A. \& Daneo-Moore, L. (1981). Effect of cerulenin on cellular autolytic and lipid metabolism during inhibition of protein synthesis in Streptococcus faecalis. Journal of Bacteriology 146, $590-604$.

Caulfield, M. P., Berkeley, R. C. W., Pepper, E. A. \& Melling, J. (1979). Export of extracellular levan sucrase by Bacillus subtilis: inhibition by cerulenin and quinacrine. Journal of Bacteriology 138, 345-351.

FeiN, J. E. \& Rogers, H. J. (1976). Autolytic enzymedeficient mutants of Bacillus subtilis 168. Journal of Bacteriology 127, 1427-1442.

Fishman, Y., Rotham, S. \& Citri, N. (1980). Preferential suppression of normal exo-enzyme formation by membrane-modifying agents. Journal of Bacteriology $141,1435$.

Higgins, M. L., Carson, D. D. \& Daneo-Moore, L. (1980). Morphological effect of cerulenin treatment on Streptococcus faecalis as studied by ultrastructure reconstruction. Journal of Bacteriology 143, 989-994.

Ito, E. T., CihlaR, R. L. \& INDERLied, C. B. (1982). Lipid synthesis during morphogenesis of Mucor racemosus. Journal of Bacteriology 152, 880-887.

JaCQues, N. A. (1983). Membrane perturbation by cerulenin modulates glucosyltransferase secretion and acetate uptake by Streptococcus salivarius. Journal of General Microbiology 129, 3293-3302.
Janczura, E., Perkins, H. R. \& Rogers, H. J. (1961). Teichuronic acid: a mucopolysaccharide in wall preparations from vegetative cells of Bacillus subtilis. Biochemical Journal 80, 82-93.

Leduc, M., KasRa, R. \& VAN Heijenoort, J. (1982). Induction and control of the autolytic system of Escherichia coli. Journal of Bacteriology 152, 26-34.

Leung, W.-L., Harlander, S. K. \& Schachtell, F. (1980). Streptococcus mutans dextransucrase: effect of cerulenin on lipid synthesis and enzyme production. Infection and Immunity 28, 846-852.

Omura, S. (1976). The antibiotic cerulenin, a novel tool for biochemistry as an inhibitor of fatty acid synthesis. Bacteriological Review's 40, 681-697.

Paton, J. C., May, B. K. \& Elliot, W. H. (1980). Cerulenin inhibits production of extracellular proteins but not membrane proteins in Bacillus amyloliquefaciens. Journal of General Microbiology 118, 178-187.

Petit-Glatron, M. F. \& Chambert, R. (1981). Levansucrase of Bacillus subtilis. Conclusive proof that production and export are unrelated to fatty acid synthesis but modulated by membrane modifying agents. European Journal of Biochemistry 119, 603611.

Rogers, H. J. (1985). Morphological changes in Bacillus subtilis with genetic and phenotypic origins. Annales de Microbiologie (in the Press).

Rogers, H. J. \& TAYLOR, C. (1978). Autolysins and shape change in rodA mutants of Bacillus subtilis. Journal of Bacteriology 135, 1032-1042.

Rogers, H. J. \& Thurman, P. F. (1978). Temperaturesensitive nature of the rod $\mathrm{B}$ mutation in Bacillus subtilis. Journal of Bacteriology 133, 298-305.

Rogers, H. J., Thurman, P. F. \& Burdett, I. D. J. (1983). The bactericidal action of $\beta$-lactam antibiotics on an autolysin-deficient strain of Bacillus 
subtilis. Journal of General Microbiology 129, 465478.

Rogers, H. J., Taylor, C., Rayter, S. \& Ward, J. B. (1984). Purification and properties of autolytic endo- $\beta$ - $N$-acetylglucosaminidase and the $N$-acetylmuramyl-L-alanine amidase from Bacillus subtilis strain 168. Journal of General Microbiology 130 , 2395-2402.

Vance, D. I., Goldberg, I., Mitsuhashi, O., Block, K., OMURA, S. \& Momura, S. (1972). Inhibition of fatty acid synthetase by the antibiotic cerulenin. Biochemical and Biophysical Research Communications 48, 649-656.

Willie, W. E., Eisenstadt, E. \& Willecke, K. (1975). Inhibition of de novo fatty acid synthesis by the antibiotic cerulenin in Bacillus subrilis: effects on citrate- $\mathrm{Mg}^{2+}$ transport and synthesis of macromolecules. Antimicrobial Agents and Chemotherapy 8, 231 237. 